\title{
A LUTA PELA TERRA, O MANGUE E O MAR: A TRAJETÓRIA DE UM MOVIMENTO SOCIOAMBIENTAL NO LITORAL DO PARÁ
}

\author{
THE FIGHT FOR LAND, THE MANGUE AND THE SEA: THE PATH OF A SOCIO- \\ EVIRONMENTAL IN THE COAST OF PARÁ
}

Paulo Victor Sousa LIMA', Tânia Guimarães RIBEIRO²

Artigo recebido em 23/03/2021, aceito em 01/07/2021, publicado em 19/09/2021.

Palavras-chave:
Amazônia;
Maretório;
Reserva Extrativista
Marinha;
Socioambientalismo.

Keywords:

Amazon;

Maretório;

Marine Extractive

Reserve;

Socio-

environmentalism.

\section{RESUMO}

Este artigo busca compreender o processo de institucionalização da Reserva Extrativista Marinha Caeté-Taperaçu, localizada no município de Bragança, no litoral do estado do Pará. A pesquisa é qualitativa, a partir da análise de fontes primárias e secundárias, atrelada a realização de entrevistas com roteiros semiestruturados. Argumenta-se que a Reserva Extrativista Marinha Caeté-Taperaçu é fruto de mobilizações protagonizadas por povos e comunidades de extrativistas costeiros-marinhos, que viram na criação deste modelo de Unidade de Conservação, uma alternativa aos conflitos socioambientais decorrentes da incorporação do litoral paraense à agenda desenvolvimentista. No entanto, a institucionalização da Reserva Extrativista Marinha Caeté-Taperaçu não resultou no fim da luta por reconhecimento de direitos ligados à terra, ao mangue e ao mar - em outras palavras, ao maretório.

\section{ABSTRACT}

This article seeks to understand the institutionalization process of the Marine Extractive Reserve Caeté-Taperaçu, located in the municipality of Bragança, on the coast of the state of Pará. The research is qualitative, based on the analysis of primary and secondary sources, linked to the realization of interviews with semi-structured scripts. It is argued that the CaetéTaperaçu Marine Extractive Reserve is the result of mobilizations led by fishing and extractivist communities and communities, which saw in the creation of this model of conservation unit, an alternative to the socio-environmental conflicts resulting from the incorporation of the Pará coast into the development agenda. However, the institutionalization of the Marine Extractive Reserve Caeté-Taperaçu did not result in the end of the struggle for the recognition of rights linked to land, mangroves and the sea - in other words, the maretório.

\footnotetext{
${ }^{1}$ Mestrando no Programa de Pós-graduação em Sociologia e Antropologia (PPGSA) da Universidade Federal do Pará (UFPA). Licenciado em Ciências Sociais pela UFPA. Integrante do Núcleo de Pesquisa Ação Pública, Território e Ambiente (ACTA). Bolsista CNPq. Orcid: http://orcid.org/0000-0002-9674-1334. E-mail: paulo.lima@ifch.ufpa.br.

${ }^{2}$ Doutora em Ciências Humanas (Sociologia) pela Universidade Federal do Rio de Janeiro (UFRJ). Docente da Faculdade de Ciências Sociais e do PPGSA da UFPA. Coordenadora do Núcleo de Ação Pública, Território e Ambiente (ACTA). Orcid: http://orcid.org/0000-0003-1683-3659. E-mail: taniagr@ufpa.br.
} 


\section{INTRODUÇÃO}

Fruto de uma longa e intensa trajetória de mobilizações sociais - protagonizadas pelos seringueiros do estado do Acre -, as Reservas Extrativistas (Resex's), são concebidas como um modelo de conservação que propõe conciliar a proteção dos recursos naturais - aqui compreendidos como bens comuns da natureza - e 0 modo de vida de grupos sociais caracterizados como populações tradicionais ${ }^{1}$ : seringueiros (as), extrativistas, pescadores (as) artesanais, marisqueiras, coletores (as) de caranguejo, coletoras de coco-babaçu, entre outros.

É sabido que o legado do seringalista Chico Mendes $^{2}$ e de seus companheiros e companheiras, ecoou para além das florestas de seringais do estado do Acre, influenciando na luta por direitos de outros grupos sociais marginalizados, a partir da década de 1980. É o caso dos povos e comunidades de extrativistas costeiromarinhos ${ }^{3}$, que viram na criação de Reservas Extrativistas Marinhas - uma ampliação do modelo "Resex" para biomas marinhos e costeiros - uma alternativa aos conflitos socioambientais, decorrentes da incorporação do litoral brasileiro à agenda desenvolvimentista.

Nesta pesquisa, entende-se por conflitos socioambientais, aqueles que envolvem: o acesso, a conservação e a posse dos bens comuns da natureza, em particular aqueles ligados à terra, ao mangue e ao mar. São tensões que, de acordo com Svampa (2016), esboçam um cenário caracterizado por uma assimetria de poder entre os grupos confrontados. E, salienta a autora, expressam diferentes concepções e valores do que é natureza, bem como do que significa desenvolvimento.

Na Amazônia, e especificamente no litoral do Pará, observa-se que a emergência de conflitos socioambientais - originando as mobilizações que demandaram - e ainda demandam - a criação de Resex's Costeiro-Marinhas ${ }^{4}$ - está atrelada à presença de grandes projetos, como a construção de estradas, rodovias e barragens; a instalação de empresas de pesca industrial acompanhada de portos; aumento populacional na disputa pelos bens comuns; degradação de mananciais e bacias hidrográficas; entre outros.

\footnotetext{
${ }^{1}$ Nesta pesquisa o termo "populações tradicionais" é empregue enquanto uma categoria política, usado de maneira "extensionista". Isso significa, de acordo com Cunha e Almeida (2001), não limitar seu uso na caracterização desses grupos sociais a partir da ideia de "baixo impacto sobre o ambiente", "ecologicamente sustentável", "aqueles que estão fora da esfera do mercado", entre outros.

2 Sobre a trajetória de mobilizações que repercutiu na criação da primeira Resex no território brasileiro, consultar por exemplo, Allegretti (1994), Almeida (2004), Diegues (1996), Gonçalves (2001), entre outros.

3 É através desta expressão que as lideranças da comissão nacional que representa esses povos e comunidades - a CONFREM se autodenominam. É interessante ressaltar que ela dialoga com o conceito de populações tradicionais sustentado por Cunha e Almeida (2001). Como consta no estatuto da comissão, o termo "povos e comunidades de extrativistas costeiro-marinhos" constituise em uma categoria em extensão: pescadores artesanais, marisqueiras, catadoras de mangaba, piaçaveiros, tiradores de caranguejo, agroextrativistas, cipozeiros, artesãos de pesca, artesãos, extrativistas, catadeiras de camarão, caiçaras, coletoras de frutíferas e sementes, coletores de algas, "possíveis inclusões".

${ }^{4}$ A expressão "Resex's Costeiro-Marinhas" é utilizada por membros da COFREM, como uma forma de se referenciar as Resex's localizadas no bioma costeiro-marinho do litoral brasileiro. Acredita-se que, a inclusão da palavra "costeiro" ao termo "Resex's Marinhas" ocorre em função de que nem todas as Unidades de Conservação decretas em regiões litorâneas carregam em seu nome a palavra "marinha". É possível também observar o emprego da expressam em documentos oficiais, ver por exemplo Fernandes e Souza (2009).
} 
Sob tal enfoque, o presente artigo tem como objetivo compreender o processo de institucionalização de uma dessas Unidades de Conservação: a Reserva Extrativista Marinha Caeté-Taperaçu, situada no município de Bragança, na região litorânea paraense. Argumenta-se que as mobilizações sociais que repercutiram na criação dessa Resex Marinha, foram desencadeadas por conflitos socioambientais ligados aos impactos produzidos por grandes projetos, como a construção da PA-458 e a instalação de empresas de pescas industriais e portos no município.

Ao partir dessa premissa, busca-se contribuir com estudos anteriores - bem como futuros - sobre a Resex Marinha Caeté-Taperaçu (Lopes, 2016; Peres, 2011; Reis da Silva, 2014; entre outros). Nestas pesquisas observou-se a presença do argumento de que sua criação surgira como uma "oferta" circunstancial do Estado brasileiro, reforçado em documentos oficiais da Reserva Extrativista Marinha Caeté-Taperaçu (Abdala, Saraiva, \& Wesley, 2012a; 2012b). Tal narrativa invisibiliza totalmente o papel desempenhado pelos povos e comunidades de extrativistas costeiro-marinhos do município de Bragança.

Dessa forma, argumenta-se como a criação da Resex Marinha Caeté-Taperaçu se assemelha às experiências do socioambientalismo na Amazônia, protagonizadas por grupos sociais marginalizados, que entrelaçam a demanda por direitos sociais e luta em defesa dos bens comuns da natureza. Esses embates em torno da proteção das florestas, das águas e dos manguezais - implicam diretamente na reprodução social, econômica e política desses grupos sociais. E, suscitam ações coletivas, produto das articulações e alianças forjadas em meio à circulação de ideias que vão do local ao internacional.

\subsection{0 maretório da Resex Marinha Caeté-Taperaçu}

Nesta pesquisa, é adotado o termo maretório para referenciar os territórios das Resex's CosteiroMarinhas situadas no litoral do Pará. De acordo com Sousa e Ribeiro (2021), trata-se de uma demanda do movimento de populações e comunidades pesqueiras e extrativistas, através de lideranças locais da Comissão Nacional para o Fortalecimento das Reservas Extrativistas e dos Povos Extrativistas Costeiros e Marinhos (CONFREM). Para esses grupos sociais, taxonomias como território e territorialidade não seriam capazes de abarcar as especificidades presentes nas Resex's Costeiro-Marinhas no litoral do Brasil. Especificidades estas, que estão entrelaçadas a um modo de vida particular de subsistir e de se reproduzir social, política e economicamente a partir de uma dinâmica socioambiental que envolve a apropriação e uso dos bens comuns da terra, do mangue e do mar.

O conceito maretório ainda está em construção no âmbito da academia. Sousa e Ribeiro (2021), ao partirem de uma literatura latino-americana, atrelada as experiências empíricas junto as Resex's CosteiroMarinhas do litoral do Pará e representantes locais da Confrem, afirmam que

(...) pensar as Resex's como "maretórios" - e em particular as Resex's Costeiro-Marinhas localizadas no litoral do Pará - é compreendê-las como um tipo de território socialmente 
constituído em meio a fluidez de uma dinâmica socioambiental, de uso e apropriação dos recursos naturais - da terra, do mangue e mar - qual, as políticas socioambientais não conseguem abarcar. E que, portanto, passa ser reivindicado pelas populações pesqueiras e extrativista do litoral do Pará, frente aos avanços constantes da agenda desenvolvimentista sobre a região (Sousa \& Ribeiro, 2021, p. 9).

Neste sentido, o maretório se traduz em um espaço relacional, que envolve um conjunto de práticas tradicionais exercidas por esses povos e comunidades de extrativistas costeiro-marinhas, desde a retirada do caranguejo do mangue, passando pela pesca artesanal e agricultura familiar. E, como será observado ao longo do artigo, a luta pelo direito destes maretórios resultaria na formação de uma identidade compartilhada por mulheres e homens que habitam a terra, o mangue e o mar (Sousa, 2019).

Atualmente, o Pará ocupa um lugar de destaque no quadro das Resex's decretadas no Brasil. Das 33 Resex's Costeiro-Marinhas, sob a gestão federal, que objetivam a proteção dos bens comuns marinhos e costeiros do litoral brasileiro, 14 estão situadas no estado (ICMBio, 2020). É o caso da Resex Marinha CaetéTaperaçu, local desta pesquisa, que fora instituída por meio do decreto presidencial de 20 de maio de 2005.

Localizada no município de Bragança, às margens do rio Caeté (entre os municípios de Tracuateua e Augusto Corrêa, os quais também abrigam Unidades de Conservação, respectivamente, a Resex Marinha de Tracuateua e Resex Marinha de Araí-Peroba), a Resex Marinha Caeté-Taperaçu fica distante cerca de $215 \mathrm{~km}$ de Belém, capital do estado do Pará. Na Figura 1 é possível observar os limites geográficos deste maretório.

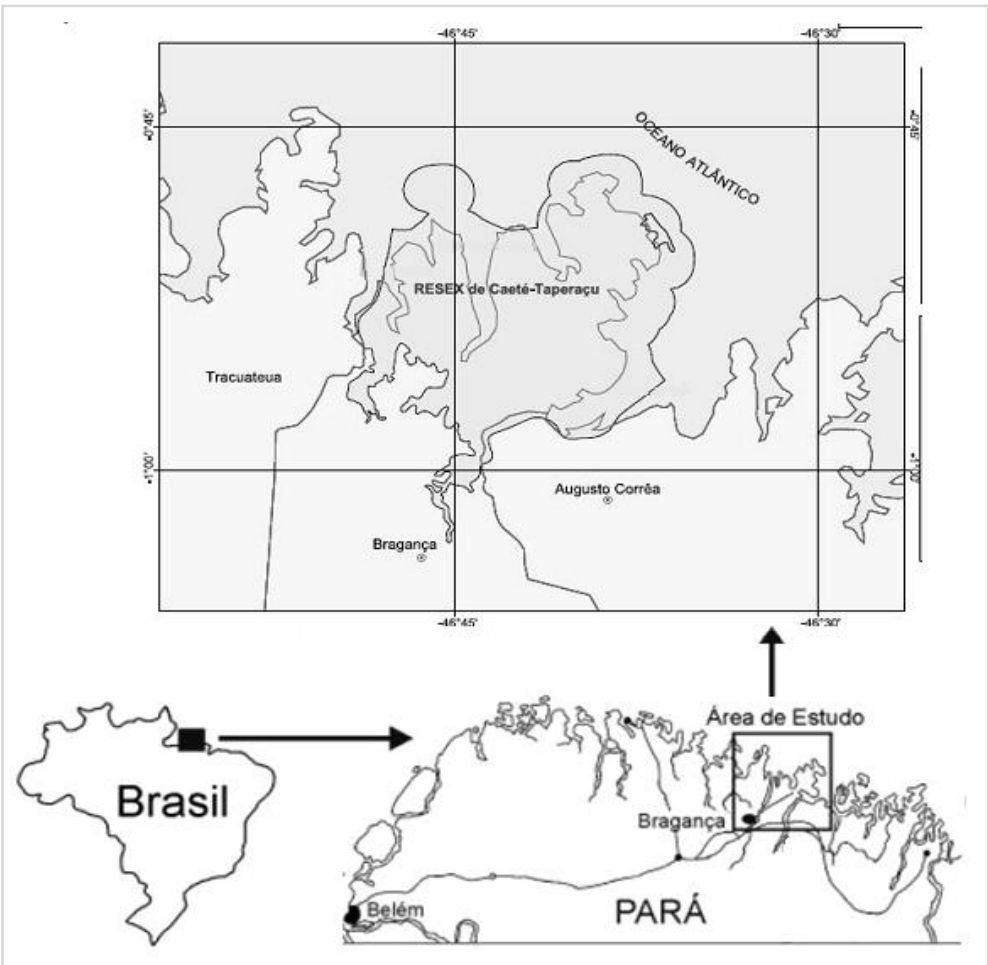

Figura 1 - Mapa da Resex Marinha Caeté-Taperaçu

Fonte: MMA/ICMBio (2017) 
Esse maretório se estende por uma área de 42.068,086 hectares, tendo em seu interior comunidades, onde vivem aproximadamente 4.500 famílias, de acordo com um levantamento realizado pela CONFREM. Em conjunto com as demais Resex's Costeiro-Marinhas no litoral do Pará, a Caeté-Taperaçu é responsável pela proteção de um importante ecossistema, tanto do ponto de vista biológico, como socioeconômico: os manguezais.

Os manguezais, em uma perspectiva biológica, são de suma importância para a sobrevivência, equilíbrio e reprodução da fauna e flora local. De acordo com o ICMBio (2018), o Brasil detém uma extensão de 1.398.966.11 hectares de manguezais em seu litoral, desta área, $83 \%$ se encontram protegidos em unidades de conservação como a Resex Marinha Caeté-Taperaçu. O estado do Pará, ocupa o segundo lugar no ranking nacional abrigando 390.589.41 hectares de manguezais - ficando atrás apenas do Maranhão, com 505.490.12 hectares (ICMBio, 2018).

Do ponto de vista socioeconômico, esses ecossistemas são de grande importância para a reprodução social, política e econômica de milhares de famílias que vivem em maretórios, com o da Resex Marinha CaetéTaperaçu. São homens, mulheres, jovens, crianças e idosos (as), que em seu cotidiano tecem relações humanas e não-humanas marcadas pela apropriação dos bens comuns da terra, do mangue e do mar. É esse esforço coletivo em ocupar, usar, controlar e se identificar com uma porção da natureza que caracteriza 0 maretório das Resex's Costeiro-Marinhas no litoral do Pará, como a Caeté-Taperaçu, bem como a maretorialidade 5 das populações pesqueiras e extrativistas que nelas vivem - 0 que se aproxima, na perspectiva de Godelier (1984) e Little (2004), em torno do território e territorialidade.

\section{MÉTODO}

A tentativa de reconstituir o processo de institucionalização da Resex Marinha Caeté-Taperaçu teve início em meados do ano de 2017, a partir do desenvolvimento de atividades no âmbito da iniciação científica vinculado ao projeto de pesquisa Território, Participação e Conservação Ambiental6, culminando em uma monografia de conclusão de curso intitulada "A minha terra é o mar: a trajetória de um movimento socioambiental no litoral da Amazônia", defendida em dezembro de 2019 - ver Sousa (2019).

Como dito anteriormente, fora observado uma ausência de estudos que objetivasse compreender o processo de criação da Caeté-Taperaçu. Em função disso, o primeiro procedimento de pesquisa adotado foi a realização de um levantamento bibliográfico de Teses e Dissertações sobre essa Unidade de Conservação. Percebeu-se que nessas pesquisas haviam espaços destinados a descrição do local de pesquisa, ou mesmo

\footnotetext{
5 Termo empregue no discurso de uma liderança comunitária e representante local da Confrem, em alternativa ao termo "territorialidade", em um Colóquio em comemoração ao aniversário de 20 anos do Sistema Nacional de Unidade de Conservação da Natureza, realizado de forma virtual entre os dias 8 e 12 de março de 2021.

${ }^{6}$ Este projeto de pesquisa contou com financiamento do Conselho Nacional de Desenvolvimento Científico e Tecnológico (CNPq).
} 
um histórico sobre a institucionalização da Resex Marinha Caeté-Taperaçu. Na maioria dos casos, tomava-se como referência o registro presente em documentos oficiais.

A partir da análise deste material, buscou-se então identificar quais eventos teriam repercutido em conflitos socioambientais na região do Caeté, desencadeando em mobilizações sociais que demandaram a criação da Resex Marinha Caeté-Taperaçu. Notou-se que tais informações coletadas, ao serem analisados em conjunto, apresentavam lacunas.

Dessa forma, com o objetivo de supri-las, adotou-se como procedimento metodológico a realização de entrevistas com roteiros semiestruturados. Foi possivel realizar um total de 9 entrevistas com diferentes interlocutores ${ }^{7}$ e interlocutoras, identificados ao longo da pesquisa, que fizeram parte das mobilizações ou que deram algum suporte. Dentre os (as) interlocutores (as) estão: lideranças comunitárias, militantes, professores (as), pesquisadores (as), políticos (as) e religiosos (as).

Por fim, no que se refere ao referencial teórico adotado para analisar as informações coletadas partiuse de uma síntese conceitual proposta por Diani (1992), que reúne a Teoria dos Novos Movimentos Sociais e a Teoria do Processo Político, para interpretarmos as mobilizações coletivas no município de Bragança. 0 sociólogo define um movimento social como "uma rede de interações informais entre uma pluralidade de indivíduos, grupos e/ou organizações, engajadas em conflitos políticos em torno de uma identidade coletiva compartilhada" (Diani, 1992, p. 1).

Outrossim, dadas as especificidades em torno das lutas populares na Amazônia, buscou-se incorporar conceitos que permitissem o aprofundamento da análise. Por exemplo, a identificação de microcontextos de mobilizações (Snow, Burke, Steven, \& Benford, 1989) atrelada ao processo denominado de ambientalização de demandas sociais (Acselrad, 2010), a perspectiva crítica dos encaixes institucionais (Lavalle, Carlos, \& Dowbor, 2017) e do repertório de interação (Abers, Serafim, \& Tatagiba, 2014) permitem a melhor compreensão da agência dos povos e comunidades de extrativistas costeiro-marinhos do município de Bragança, diante de uma estrutura de oportunidade (Tarrow, 1998). Ademais, a emergência de uma identidade coletiva compartilhada (Melucci, 1980) atrelada à defesa deste maretório, constitui-se em um elemento de suma importância para análise deste movimento socioambiental.

\section{RESULTADOS E DISCUSSÃO}

Os resultados e discussão apresentados a seguir, buscam sustentar 0 argumento de que a institucionalização da Resex Marinha Caeté-Taperaçu se insere em um contexto marcado por lutas e embates

\footnotetext{
${ }^{7}$ A adoção dos termos "interlocutores" e "interlocutoras", justifica-se pelo fato de se compreender a pesquisa como uma relação de mão dupla. Isto é, há uma relação de troca e participação ativa no trabalho. E dessa forma, não se caracterizam como meros informantes, e, por vezes, direcionam a pesquisa.
} 
protagonizados por grupos marginalizados - como pescadores (as) artesanais, coletores (as) de caranguejos, pequenos (as) agricultores (as), entre outros - do município de Bragança na defesa dos bens comuns da terra, do mangue e do mar frente aos impactos causados pelo avanço da agenda desenvolvimentista sobre a região.

Na Figura 2 é possível observar uma síntese dos principais eventos em torno do processo de criação da Resex Marinha Caeté-Taperaçu. Nota-se o papel desempenhado pelos povos e comunidades de extrativistas costeiro-marinhos do município de Bragança, a partir da formação de organizações locais reivindicando direitos sociais, que por ora, ainda não estavam relacionadas à criação de uma Unidade Conservação na região.

No entanto, ao passo que esses grupos sociais, e em particular as lideranças comunitárias, forjam alianças com diferentes atores e organizações locais e extralocais - técnicos, pesquisadores, acadêmicos em uma conjuntura (nacional e internacional) favorável à pauta socioambiental, observa-se o desencadeamento de um processo denominado de ambientalização das demandas sociais. O movimento socioambiental que se constituiu objetivando a criação da Resex Marinha produziu um repertório de estratégias para enfrentar grupos de opositores.

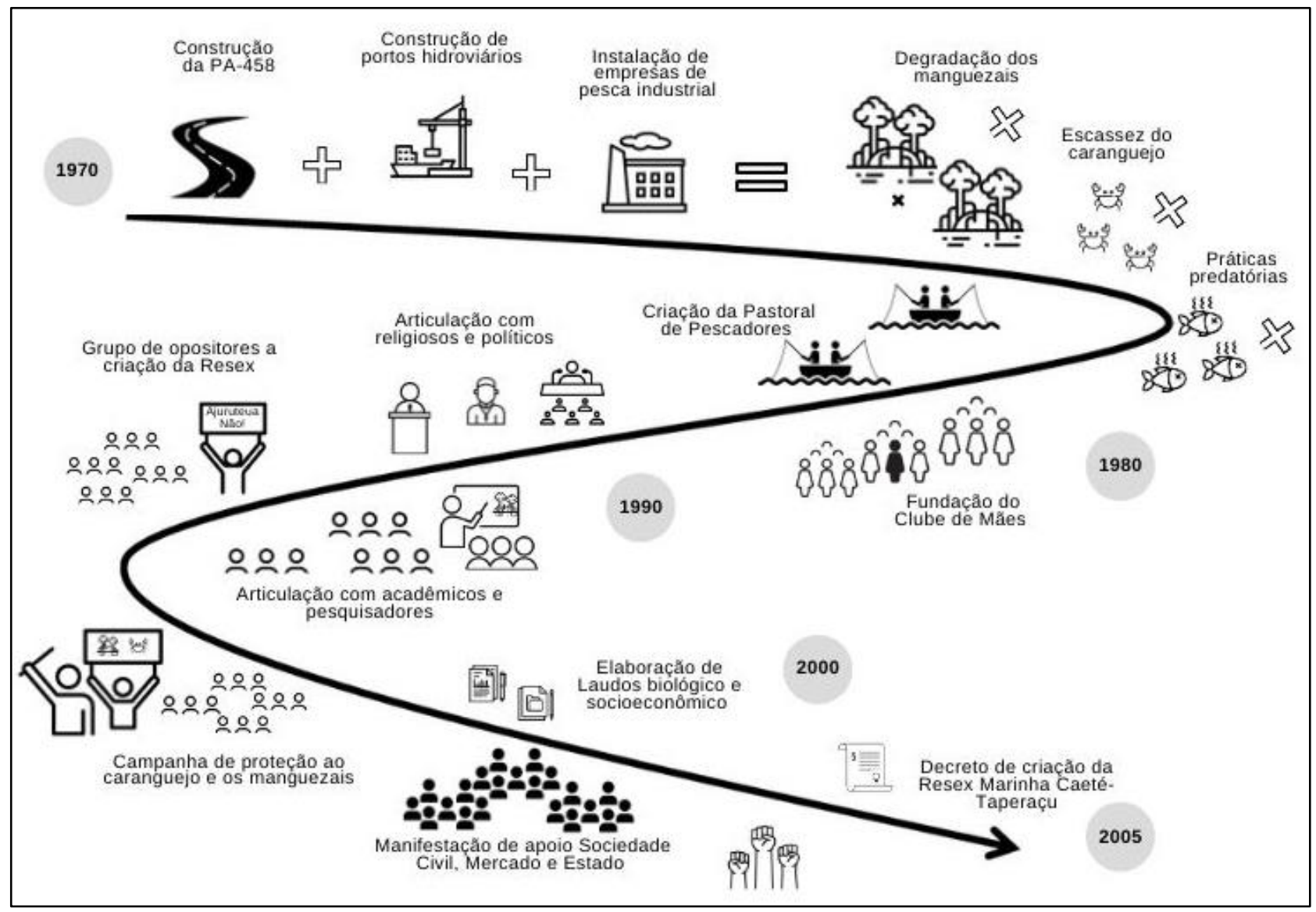

Figura 2 - Linha do tempo da criação da Resex Marinha Caeté-Taperaçu

Fonte: Elaboração do Autor e da Autora. 
Ressalta-se que a tentativa de reconstituir a trajetória desses eventos, em um plano linear, se justifica apenas como um recurso metodológico para apresentar o caminho percorrido na narrativa dos interlocutores e das interlocutoras, bem como dos dados coletados em fontes primárias e secundárias. Pois, no plano real, os fatos e ações se entrelaçam formando uma trama que liga diferentes perspectivas e acontecimentos em diferentes níveis de tempo e espaço.

\subsection{A marcha forçada para o progresso e desenvolvimento na região do Caeté}

A partir da década de 1970, o município localizado às margens do rio Caeté, passou a ser alvo da agenda desenvolvimentista do estado do Pará, que objetivava estimular o turismo e a economia local. A chegada de grandes projetos e empreendimentos produziu profundos impactos ambientais, e consequentemente sob o modo de vida de famílias de pescadores (as) artesanais, coletores (as) de caranguejos, pequenos (as) agricultores (as), entre outros. A seguir será dado destaque a dois eventos que repercutiram em conflitos socioambientais na região.

O processo que ocorre nesse pedaço da Amazônia é parte de um contexto mais amplo que atinge a região como um todo e o próprio país. A "marcha forçada" da modernização se configura nas grandes obras que marcam o avanço do Estado sobre a Amazônia abrindo espaço para os empreendimentos privados. Essa parceria denota o avanço do capital privatizando terras, deslocando populações locais, destruindo a natureza. Rios, florestas e comunidades dão lugar às rodovias que ligam o norte ao centro-sul do Brasil, aos enclaves extrativistas industriais, às monoculturas do plantio e à criação de animais para exportação; bem como, às barragens que desalojam diversas populações do seu lugar. Travestido pelas ideias do desenvolvimentismo, 0 capital subjuga gente e natureza na Amazônia.

Os conflitos sociais e ambientais são marcas que passam a caracterizar a dinâmica da luta pelos territórios, com nítidas desvantagens para as populações locais que enfrentam o Estado e as forças do mercado. No caso do nordeste paraense, serão destacados dois eventos que ilustram de forma específica conflitos que marcam o avanço dos empreendimentos capitalistas sobre o território - ou melhor o maretório.

O primeiro, consiste no projeto de infraestrutura da rodovia PA-458, a qual objetivava viabilizar o acesso do centro do município de Bragança a um dos principais pontos turísticos do litoral paraense: a praia de Ajuruteua. A construção da estrada teve início em meados dos anos 1970, e ocorreu em várias etapas incluindo ampliações, melhoramentos e asfaltamento -, sendo finalizada apenas em 1991 (Oliveira, 2015). Sua conclusão, ocasionou no aterro de cerca de $26 \mathrm{~km}$ de florestas de manguezais, resultando em profundas alterações na sociobiodiversidade das proximidades (Oliveira \& Maneschy, 2014). Em particular, nas localidades do Acarajó e Bacuriteua, ambas comunidades caracterizadas pela sua dependência socioeconômica da coleta e catação do caranguejo-uçá (Peres, 2011; Reis da Silva, 2014). 
O segundo evento em destaque, diz respeito à instalação de empresas de pesca industrial, atreladas a construção de portos para os embarques e desembarques de navios de grande porte. No município de Bragança, existe o registro de 14 empresas instaladas entre os anos de 1983 e 2013 (Brasil, 2019). Até 2005, ano de criação da Resex Marinha Caeté-Taperaçu, havia 8 polos pesqueiros ativos na região competindo com a pesca artesanal.

Observa-se assim, que tal cenário se configura em palco para a emergência de conflitos socioambientais envolvendo os bens comuns do município de Bragança. No caso da PA-458, os impactos se, estendem em particular aos manguezais da região. Por um lado, a melhor acessibilidade à localidade - e consequentemente ao aumento de trabalhadores -, resultou na escassez de caranguejos, em virtude da captura discriminatória de fêmeas da espécie - durante o período de ovulação, desova e troca de carapaças exercidas por grupos de trabalhadores de municípios vizinhos, bem como da população urbana de Bragança (Costa, 2012). Por outro, em função da construção da PA-458, como destacados por interlocutores (as), os caranguejos migraram para locais mais afastados, resultando em um maior esforço dos (as) trabalhadores (as) na captura dos crustáceos.

Ademais, nos depoimentos, verificou-se uma associação entre a instalação das empresas de pesca industrial e dos portos, com o estímulo de práticas predatórias na região, as quais causaram impactos na pesca artesanal. Paralelo a isso, essas práticas foram incorporadas pelos pescadores artesanais como uma forma de conseguir uma quantidade maior de pescados para o sustento de suas famílias.

Na seção a seguir será possível observar que em resposta a esses conflitos socioambientais, houve o aparecimento de formas de resistência, a partir de organizações locais. Ressalta-se que essas organizações não surgiram demandando a criação da Resex Marinha Caeté-Taperaçu.

\subsection{0 clube de mães e a pastoral de pescadores}

A ideia de microcontextos de mobilizações tornou-se para esta pesquisa um importante recurso metodológico, auxiliando na identificação de organizações locais e extralocais envolvidas no processo de mobilizações para a criação da Resex Marinha Caeté-Taperaçu.

De acordo com Snow et. al. (1989), os microcontextos de mobilizações caracterizam-se, por conexões entre indivíduos que são regadas por interpretações comuns de mundo, laços afetivos e lealdade comunitária, o que resulta em um sentimento de pertencimento a um grupo. A análise dessas interações sociais, afirmam os autores, permite, por exemplo, compreender como cidadãos comuns tornam-se ambientalistas.

Ao longo da realização desta pesquisa foram identificados cinco microcontextos de mobilizações. Nessa seção em particular serão destacados dois, por revelar a agência da população pesqueira e extrativista do município de Bragança, a partir da articulação de liderança comunitárias na formação de organizações 
locais. Essas mobilizações emergiram em função dos conflitos socioambientais, decorrentes da presença dos grandes projetos e empreendimentos citados anteriormente.

Entre as comunidades do Acarajó e do Bacuriteua, localizadas às margens da PA-458, situa-se o primeiro microcontexto de mobilização identificado. Como dito, essas localidades são caracterizadas por uma forte dependência social, política e econômica do extrativismo nos manguezais, e foram profundamente impactadas pela construção da PA-458. O perigo da escassez da principal fonte de renda familiar, atrelado ao aumento de problemas sociais - como índices de alcoolismo entre os trabalhadores homens - resultou nos esforços de um grupo de mulheres, em particular lideranças comunitárias, com o apoio de uma técnica e extensionista rural da Empresa de Assistência Técnica Rural do Estado do Pará (Emater-PA), a fundar um Clube de Mães nos anos 1980.

Essa organização comunitária tinha, a princípio, um caráter assistencialista oferecendo cursos profissionalizantes para as mulheres dessas comunidades - como a fabricação de bolos e doces, pinturas em tecidos, confecções de redes, entre outros - administrados por elas mesmas. O lucro obtido pela venda dos produtos fabricados pelo Clube de Mães era divido entre essas mulheres, garantindo assim, uma fonte de renda extra para suas famílias (Costa, 2014).

As interlocutoras ressaltaram que, através do Clube de Mães as mulheres do Acarajó e do Bacuriteua alcançaram reconhecimento do poder público local, estadual e federal. $O$ engajamento de mulheres e lideranças comunitárias culminou em mobilizações pautando as autoridades competentes a implantação de uma creche e de uma escola de ensino fundamental, onde essas mães de famílias poderiam deixar em segurança seus filhos.

Posteriormente, o Clube de Mães foi ampliado, em função da participação de grupo de jovens das comunidades, bem como dos companheiros dessas mulheres, transformando-se na Associação União Comunitária do Acarajó (Aura). Essa associação representou, naquele momento, um instrumento de luta política para os moradores, cujas demandas incluíam o reconhecimento da categoria de coletor (a) e catador (a) de caranguejo.

É na comunidade do Castelo, localidade caracterizada pela sua tradição com a pesca artesanal, que se situa o segundo microcontexto de mobilização identificado. Essa comunidade, como outras, ligada a pesca em pequena escala, foi profundamente impactada pela instalação das empresas de pesca industrial e os portos para o embarque e desembarque de embarcações de grande porte.

Somado a isso, os interlocutores apontaram para os conflitos em torno da Colônia de Pescadores Z17. De acordo com Diegues (2004), grande parte das colônias de pescadores no Brasil eram presididas por políticos locais, comerciantes e latifundiários. A ausência de pescadores artesanais nesses cargos era justificada, segundo o autor, pelo fato desses trabalhadores não conseguirem aliar as demandas associativistas, com o sustento familiar. 
No entanto, a partir da década de 1980, essa estrutura passou a ser questionada pelos próprios pescadores artesanais, que começaram a se articular em organizações locais (Campos, 1993). Na comunidade do Castelo, por exemplo, houve a criação de uma Pastoral de Pescadores. De acordo com interlocutores, essa organização fora resultado da articulação de grupo de pescadores, em particular lideranças comunitárias, com o clero de Bragança, e integrantes do Movimento de Pescadores do Estado do Pará (MOPEPA), representante local do Movimento Nacional de Pescadores e Pescadoras (MONAPE).

A partir dos esforços, logo em seus anos iniciais de criação, a Pastoral de Pescadores da comunidade Castelo conseguiu lançar a candidatura de uma chapa eleitoral formada por pescadores artesanais, para disputar as eleições para presidência da Colônia de Pescadores Z-17. Todavia, como rememorado por um dos interlocutores, não fora obtida vitória.

Com base em depoimentos, observa-se que a fundação de organizações sociais, como o Clube de Mães e Pastoral de Pescadores, repercutiu na canalização de aspirações desses grupos que chegaram a participar de espaços como o I, II e III Grito do Campo, realizado em Belém, capital do estado do Pará, entre os anos de 1990 e 1992. Segundo Campos (1993), o Grito do Campo se caracterizou como um evento que reuniu trabalhadores rurais do estado do Pará, com o objetivo de pressionar as autoridades para que oferecessem melhores condições de vida para homens e mulheres no campo.

Como observado até aqui, tanto a fundação do Clube de Mães quanto à da Pastoral de Pescadores não estavam relacionadas a mobilizações demandando a implementação de uma Unidade de Conservação da região do Caeté. Tais organizações visavam resolver questões mais imediatas. Buscavam soluções para os conflitos no tocante a pesca, a extração do caranguejo e outros problemas sociais. Todavia, a seguir busca-se demonstrar, como a presença de um terceiro microcontexto de mobilização, desencadeou um processo denominado de ambientalização das demandas sociais.

\subsection{A ambientalização das demandas sociais}

É sabido, que o crescimento e a consolidação do socioambientalismo no Brasil, influenciaram nas lutas populares na Amazônia por direitos sociais. Pois, o debate internacional acerca da questão ambiental favoreceu uma nova percepção sobre o meio ambiente e, mais adiante, sobre os problemas sociais relacionados ao uso dos bens comuns da natureza. Isso se deu, sobretudo, pela ampliação do espaço da sociedade civil - sindicatos rurais e associações locais -, unificando bandeiras de "proteção do meio ambiente" aliada a pautas de justiça social, luta contra pobreza e desigualdade social (Acselrad, 2010).

Como base nos achados da pesquisa, o processo de ambientalização da luta da população pesqueira e extrativista do município de Bragança teve início a partir das alianças articuladas entre seus representantes 
com atores locais e extralocais, que compõem um terceiro microcontexto de mobilização caracterizado pela presença de Acadêmicos (as), Pesquisadores (as) e Técnicos (as).

Entre os anos de 1995 e 2005, o município de Bragança fora local de estudo do Grupo de Pesquisa Alemão Mangrove Dynamics and Management (Madam), o qual reuniu pesquisadores (as) nacionais e internacionais, numa parceria entre a Alemanha e o Brasil, com foco de estudos nas zonas de manguezais na costa bragantina (Abdala et. al., 2012b). Os resultados dessas pesquisas, realizadas em parceria com pesquisadores (as) da Universidade Federal do Pará (UFPa), foram fundamentais para a elaboração de laudos biológicos e socioeconômicos que apontavam para os riscos socioambientais em torno da degradação dos manguezais.

Além desses pesquisadores (as) e acadêmicos (as), os (as) interlocutores (as) fizeram referência a presença de técnicos (as) de órgãos e empresas do Estado, dentre eles, o Instituto Brasileiro de Meio Ambiente e dos Recursos Naturais Renováveis (IBAMA); o então Centro Nacional de Pesquisa e Conservação da Sociodiversidade, associado aos Povos e Comunidades Tradicionais (CNPT); e a presença da Empresa de Assistência Técnica e Extensão Rural do Estado do Pará (Emater-PA), como foi observado na articulação para criação do Clube de Mães.

Observa-se que esse conjunto de instituições proporcionou a fomentação do que a literatura dos movimentos sociais interpreta como canais de participação (Lopes \& Heredia, 2014), na medida em que, propiciaram além de recursos humanos, a oferta de veículos e verbas para a promoção de eventos, seminários e encontros - espaços destinados para a troca de experiências.

Os achados apontam que as primeiras articulações tiveram início em reuniões realizadas no Clube de Mães. Em uma delas, foi pautada a necessidade de promover uma mobilização de caráter educativo, visando à proteção das fêmeas da espécie do caranguejo-uçá - denominada popularmente como condessa. Surgira então, a ideia de promover a $1^{\text {a }}$ Campanha de Proteção ao Caranguejo e Projeto de Educação Ambiental, realizado no ano de 1995 (Costa, 2014). De acordo com os (as) interlocutores (as), essa campanha contou com a participação de aproximadamente 500 pessoas, dentre os quais lideranças comunitárias vindas de municípios vizinhos que compartilhavam dos mesmos conflitos socioambientais, decorrentes da instalação de grandes empreendimentos e projetos; e representantes de diferentes esferas do poder público.

Outro exemplo foi a realização da $1^{\text {a }}$ Conferência do Caranguejo também no município de Bragança, no ano de 1996. Os (as) interlocutores (as) afirmaram que neste evento houve a participação de um número muito próximo do anterior. 0 destaque dado a essa conferência, está vinculado aos primeiros registros de mobilizações sociais associadas à criação de reservas extrativistas marinhas no litoral do Pará, como alternativa aos conflitos socioambientais vividos por essas populações pesqueiras e extrativistas. 
Como fora observado nessa seção, a presença dos (as) técnicos (as), pesquisadores (as) influenciou na forma como a população pesqueira e extrativista do município de Bragança enxergava sua sobrevivência sendo diretamente ameaçada. Na condição de experts, tanto dentro da academia, quanto nas instituições oficiais dos diversos níveis de poder, foi se fortalecendo um ideal de sustentabilidade social associada à conservação do meio ambiente.

Todavia, cabe considerar que a formulação de um discurso técnico-científico não é consensual para os demais atores sociais, bem como, torna-se fonte de atrito frente às ontologias nas quais as populações tradicionais concebem a sua relação sociedade-natureza.

\subsection{A conjuntura nacional e internacional e a pauta socioambiental}

A partir da análise das informações contidas em documento oficiais da Resex Marinha Caeté-Taperaçu (Abdala et al., 2012a; 2012b), observou-se o encobrimento do contexto político nacional e internacional em que se insere a institucionalização dessa e de outras Unidades de Conservação na Amazônia.

De acordo com Tarrow (1998), os movimentos sociais geralmente surgem quando existe aumento de oportunidades políticas, isto é, a abertura de canais favoráveis na sociedade, para que grupos desprivilegiados possam fazer suas reivindicações. É possível identificar o surgimento de estruturas de oportunidades políticas a partir de três elementos: i) aumento de permeabilidade das instituições políticas e administrativas às reivindicações da sociedade civil; ii) mudanças no estilo de interações políticas entre o Estado e os movimentos sociais; iii) a presença de aliados potenciais, como movimentos sociais, partidos políticos, mídia e elites dissidentes.

Neste sentido, observa-se que, paralelamente à emergência de microcontextos de mobilizações no município de Bragança, configurou-se no cenário internacional, nacional e mesmo local, estruturas de oportunidades políticas que contribuíram para que o movimento socioambiental que vinha se constituindo, demandasse a criação da Resex Marinha Caeté-Taperaçu.

Como citado anteriormente, a região do Caeté fora local de pesquisa do grupo Madam. Essa parceria bilateral entre o governo Alemão e do Brasil, contou com o financiamento do Projeto Piloto de Proteção as Florestais Tropicais do Brasil (PPG-7), uma iniciativa em conjunto dos 7 países mais industrializados do mundo, incluindo também os Países Baixos, o Banco Mundial e o Governo do Brasil (Antoni, 2010). Dentre as linhas de financiamento havia uma que visava à conservação de áreas protegidas.

O PPG-7 ficou ativo por quase duas décadas, sendo iniciado em 1990 e estendendo até 2009. Sua criação está vinculada ao aumento da visibilidade do movimento socioambientalista no cenário internacional, e que no Brasil ganhou grande repercussão com o assassinato do seringalista e militante, Francisco Alves Mendes Filho, mais conhecido como Chico Mendes (1944-1988). 
Outro elemento que agregou a luta das populações tradicionais na Amazônia foi a aprovação no Congresso brasileiro da Lei na 9.985 em 18 de julho do ano 2000, que institui o Sistema Nacional de Unidades de Conservação da Natureza (SNUC). Esta lei veio a fortalecer a luta por direitos reivindicados pelo movimento socioambientalista, com o Estado brasileiro reconhecendo o dever em assegurar a proteção dos bens comuns da natureza, bem como do modo de vida de populações tradicionais. Neste sentido, com o SNUC o modelo "Resex" ganhou maior legitimidade, ampliando as possibilidades para o surgimento de novas unidades no território brasileiro.

Por fim, também foi observada uma conjuntura política favorável à criação da Resex Marinha CaetéTaperaçu. No Quadro 1, é possível verificar o número de Resex's instituídas por gestão do governo federal, entre os anos de 1994 e 2018 :

Quadro 1 - $\mathrm{N}^{\mathrm{a}}$ de Resex's decretas no Brasil por governo

\begin{tabular}{|l|c|}
\hline \multicolumn{1}{|c|}{ PRESIDENTE (A) } & Na DE RESEX'S DECRETADAS \\
\hline Fernando Henrique Cardoso (1994-2002) & 20 \\
\hline Luiz Inácio Lula da Silva (2003-2010) & $\mathbf{3 0}$ \\
\hline Dilma Rousseff (2011 a 11 de maio de 2016) & 4 \\
\hline Michel Temer (de 12 de maio de 2016 a 2018) & 58 \\
\hline Total & 4 \\
\hline
\end{tabular}

Fonte: ICMBio (2020)

Salvo as críticas direcionadas aos partidos progressistas que chegaram ao poder na América Latina, e sua aproximação com a agenda desenvolvimentista, que valoriza a natureza enquanto mercadoria, nota-se no quadro 1 que o governo petista de Luiz Inácio Lula da Silva, foi o que mais acumulou decretos de criação de Resex's no território brasileiro, dentre elas a Resex Marinha Caeté-Taperaçu. Os (as) interlocutores (as) apontam a presença de Maria Osmarina da Silva Vaz de Lima, conhecida como Marina Silva ${ }^{8}$, então Ministra do Meio Ambiente (MMA), como um fato importante, haja vista seu envolvimento com o movimento dos seringueiros no estado do Acre.

É importante ressaltar que os elementos que compõem o desenho desta estrutura de oportunidades políticas foram apresentados pelos (as) interlocutores (as) desta pesquisa, sobretudo as lideranças comunitárias envolvidas nas mobilizações. Acredita-se que isso reforça o argumento de que os povos e comunidades de extrativistas costeiro-marinhos do município de Bragança, não se caracterizam como sujeitos

\footnotetext{
8 Sobre a trajetória de Marina Silva no movimento socioambientalista, consultar, por exemplo, a tese de doutorado intitulado "Movimento para as instituições: ambientalistas, partidos políticos e a liderança de Marina Silva" (Oliveira, 2016).
} 
passivos no processo, pelo contrário, demonstram sua agência ao identificar e se beneficiar de tal estrutura favorável as suas demandas.

\subsection{Entre ação e interação: as estratégias utilizadas pelo movimento socioambiental}

Como foi observado anteriormente, não basta haver uma estrutura de oportunidades políticas para demandas sociais, é necessário que os (as) integrantes do movimento socioambiental consigam identificá-la e assim, usá-la a seu favor. Isso exige do grupo a composição de um repertório de ação (Tilly, 2010), isto é, um conjunto de estratégias, tendo em vista alcançar seus objetivos. Abers et. al. (2014), ao tomarem as mobilizações no Brasil como objetivo de análise, defendem uma ampliação do conceito repertório de ação definido por Tilly (2010).

De acordo com as autoras, no contexto brasileiro, as estratégias forjadas não necessariamente implicam em relações conflituosas entre um grupo de desafiantes de um lado, e detentores de poder do outro. Pelo contrário, é observado por Abers et. al. (2014) uma relação de cooperação entre atores coletivos e 0 Estado. Não se trata assim, de um repertório de confronto, mas sim um repertório de interação. Uma vez que, dependendo dos objetivos e alcance do movimento social, ele poderia ocupar cargos públicos, estabelecendo uma interação socioestatal e influenciando na produção de políticas públicas - os encaixes institucionais (Lavalle et. al. 2017).

No caso das mobilizações sociais no município de Bragança, demandando a criação da Resex Marinha Caeté-Taperaçu, o repertório do movimento socioambiental constituído, compôs estratégias de ações de confronto direito, bem como de interação socioestatal.

De acordo com interlocutores (as), houve um grande número de denúncias enviadas a órgãos responsáveis, como o IBAMA. Esses documentos relatam conflitos socioambientais, envolvendo a disputa pelos bens comuns naturais na região do Caeté. Em função disso, técnicos e pesquisadores ligados ao MMA e ao IBAMA foram ao encontro das lideranças comunitárias, responsáveis pelo envio das denúncias, apresentar a proposta de criação de uma Resex Marinha na região, como uma alternativa aos conflitos socioambientais relatados.

Em função disso, esses povos e comunidades de extrativistas costeiro-marinhos deram início as suas articulações, tendo em vista a coleta de assinaturas para a composição do abaixo-assinado requisitando a criação da Resex Marinha Caeté-Taperaçu no município de Bragança. É interessante ressaltar que nesse processo houve a institucionalização de um movimento social denominado Movimento pela Maré. Tendo a adesão de diferentes esferas sociais, o Movimento pela Maré alcançou seu objetivo, ao coletar uma expressiva massa de documentos assinados por representantes da Sociedade Civil, do Estado e do Mercado, apoiando a criação da Resex Marinha na região. 
Como dito, além de um repertório de ação este movimento socioambiental forjou também estratégias de interações socioestatais. Nesse processo, observa-se a presença de um quarto micro-contexto de mobilizações caracterizado pela presença de religiosos e políticos. Sob a coordenação de um então pároco da diocese de Bragança, as lideranças comunitárias conseguiram elaborar um projeto para a criação de uma Secretaria de Pesca para o município. A ideia era apresentar tal proposta aos candidatos à prefeitura da época. O resultado disso foi a eleição do candidato que apoiou a ideia de instituir a pasta, e nomeou como primeiro secretário de pesca do município Bragança, o então pároco.

Nessa mesma direção, o movimento socioambiental, com o apoio da população local, conseguiu eleger outros aliados para cargos públicos. Assim, ao lançarem à esfera do executivo (local) e legislativo (regional), estes atores forjaram o que a literatura interpreta como encaixes institucionais (Lavalle, et. al., 2017), a partir da ocupação de apoiadores ao movimento na câmara de deputados e de vereadores, na prefeitura e nas secretarias municipais.

A partir dessa amostra do repertório de estratégias produzido pelo movimento socioambiental, foi possível observar como suas ações ultrapassam a esfera de atuação da Sociedade Civil.

\subsection{A identidade forjada em torno da defesa da terra, do mangue e mar}

No campo teórico dos movimentos sociais, a análise da formação de uma identidade coletiva constituise em uma importante oportunidade para se compreender o que motiva indivíduos a participarem de mobilizações em conjunto com outros sujeitos. De acordo com Melucci (1980), essa identidade é produto de uma ação forjada em meio a tensão entre diferentes atores que compõem o grupo, e está sujeito a manipulação. Grupos específicos, salienta o autor, forjam sua identidade coletiva a partir de experiências comuns antes da constituição do movimento social.

No processo de mobilizações demandando a criação da Resex Marinha Caeté-Taperaçu, no município de Bragança, observou-se o aparecimento de um grupo de oposição - o qual caracteriza o quinto microcontexto de mobilizações identificado. Esse movimento se concentrava na região da praia de Ajuruteua. E seu surgimento está atrelado à finalização da PA-458. O melhoramento no acesso ao ponto turístico fomentou a construção de uma rede de hotelaria na região. Os proprietários desses hotéis e pousadas passaram a incorporar a mão de obra local em seu quadro de funcionários.

Esses empresários disseminaram um discurso "conservador", afirmando que a criação de uma Unidade de Conservação da região resultaria no fim desses empreendimentos, e consequentemente na oferta de emprego para a população local. Segundo os (as) interlocutores (as), o discurso recebeu apoio de diferentes atores e organizações, dentre grupos de pescadores artesanais, técnicos da Emater-PA e políticos com interesses distintos. Na atualidade, os resultados dessas mobilizações contrárias a institucionalização da Resex 
Marinha Caeté-Taperaçu podem ser observados nos limites geográficos de seu maretório: a praia de Ajuruteua, não faz parte da Unidade de Conservação.

A principal estratégia adotada para se opor a esse grupo, de acordo com interlocutores (as), foi a apropriação do discurso dos ideais do socioambientalismo e sua ressignificação na causa local. Isto é, defenderam que a solução para os conflitos socioambientais vividos por essas populações pesqueiras e extrativistas, estaria atrelada à proposta de um modelo de sociedade sustentável.

Compreende-se que neste contexto, a formação de uma identidade coletiva ocorreu a partir do alinhamento de quadros de cada grupo - apresentados através dos microcontextos -, no qual interesses particulares deram lugar, por ora, a um objetivo coletivo: a preservação dos bens comuns da região do Caeté - o maretório de Bragança. Nessa direção, um conjunto de eventos entrelaçaram interesses locais, nacionais e internacionais, tendo como desfecho a criação da Resex Marinha Caeté-Taperaçu, em maio de 2005.

\section{CONCLUSÕES}

Com base no que foi exposto, é possível inferir que as mobilizações sociais atreladas a criação da Resex Marinha Caeté-Taperaçu, constituíssem num dos esboços do socioambientalismo na Amazônia. Ao se caracterizar - em parte - pela comunhão das experiências agregadas, no decorrer dos processos de resistência protagonizadas por esses povos e comunidades de extrativistas costeiro-marinhos na defesa dos bens comuns das florestas, dos manguezais, dos mares. Essas lutas foram invisibilizadas pela literatura brasileira que objetivou traçar a identidade do socioambientalismo no Brasil, ao privilegiar em sua análise as ações coletivas no eixo sul-sudeste do país - ver por exemplo, Agripa (2003); Alonso, Costa, \& Maciel (2007); Viola (1987); Viola \& Viera (1992).

Em relação aos procedimentos metodológicos adotados ao longo desta pesquisa, a identificação de microcontextos de mobilizações ganhou destaque ao revelar a agência dos povos e comunidades de extrativistas costeiro-marinhos, do município de Bragança, inviabilizada em estudos anteriores (Lopes, 2016; Peres, 2011; Reis da Silva, 2014; entre outros). Foi o caso das mulheres das comunidades do Acarajó e do Bacuriteua, bem como dos pescadores (as) artesanais da comunidade do Castelo.

Observa-se que a institucionalização da Resex Marinha Caeté-Taperaçu não resultou no fim dos embates por direitos sociais desses grupos. Pelo contrário, verifica-se um processo contínuo, articulado entre pequenas vitórias e lutas constantes. Uma vez que, as antigas lideranças, reinventam seu repertório de estratégia a partir de bandeiras de luta da CONFREM, como a do maretório e da maretorialidade.

Por fim, o reconhecimento do histórico desse movimento socioambiental é matéria-prima para que as novas gerações compreendam esse passado recente e o ressignifique em vista da proteção deste maretório. Uma vez que, a conquista da Resex Marinha Caeté-Taperaçu - mesmo tutelada por uma instituição do Estado 
e regulada pela posse provisória da terra - ainda sofre severas ameaças em vista de um projeto político de desmantelamento dos ganhos até aqui, em vista das decisões governamentais recentes que atingem as políticas socioambientais. Os dispositivos de proteção considerados sensíveis, agora começam a ruir com as ameaças de recategorização dessas Unidades de Conservação, processo já em curso.

\section{REFERÊNCIAS}

Abers, R., Serafim, L., \& Tatagiba, F. (2014).

Repertório de interação estado-sociedade em um estado heterogêneo: a experiência na era Lula. Dados, Revista de Ciências Sociais. V. (57), pp.325-357. Retrieved from https://www.scielo.br/pdf/dados/v57n2/a03v57n2.pdf

Abdala, G., Saraiva, N., \& Wesley, F. (2012a). Plano de manejo da Reserva Extrativista Marinha CaetéTaperaçu (PA), Volume I - Diagnóstico da Unidade de Conservação. Retrieved from Volume I - Diagnostico Caete-Taperacu_final (icmbio.gov.br)

Abdala, G., Saraiva, N., \& Wesley, F. (2012b). Plano de manejo da Reserva Extrativista Marinha CaetéTaperaçu (PA), Volume II - Planejamento das Unidades. ICMBio. Brasília. Retrieved from Volume II Planejamento_Caete-Taperacu_final (icmbio.gov.br)

Acselrad, H. (2010). Ambientalização das lutas sociais - 0 caso do movimento por justiça ambiental. Revista Estudos Avançados. V. (68), pp. 103-109. Retrieved from Henri Acselrad.indd (scielo.br)

Agripa, A. (2003). A perda da radicalidade do movimento ambientalista brasileiro uma nova contribuição à crítica do movimento. Revista Ambiente e Educação. V. (8), pp. 73-94. Retrieved from Vista do A perda da radicalidade do Movimento Ambientalista Brasileiro: uma nova contribuição à crítica do movimento (furg.br)

Almeida, M. (2004). Direito à floresta e ambientalismo: seringueiros e suas lutas. Revista Brasileira de Ciências Sociais. V. (19), pp. 33-53. Retrieved from a03v1955.pdf (scielo.br)

Allegretti, M. (1994). Reservas Extrativistas: uma proposta de desenvolvimento da floresta amazônica. In Aderson, A. (Org.). $O$ destino da floresta: reservas extrativistas e desenvolvimento sustentável na Amazônia. (pp. 120-134). Rio de Janeiro. Instituto de Estudos Amazônicos.
Alonso, A., Costa, V., \& Maciel, D. (2007). Identidade e estratégia na formação do movimento ambientalista brasileiro. Revista Novos Estudos. v (79), pp. 151-167. Retrieved from untitled (scielo.br)

Antoni, G. (2010). O Programa Piloto para Proteção das Florestas Tropicais do Brasil (PPG-7) e a globalização da Amazônia. Revista Ambiente \& Sociedade. V. (14), pp. 299-313. Retrieved from AmbSoc_V13_N2.indb (scielo.br)

Brasil (2019). Lista de Empresas de Pesca de peixes em água doce em Bragança - PA. Disponível: https://empresasdobrasil.com/empresas/bragançapa/pesca-depeixes-em-agua-doce

Campos, A. (1993). Movimentos sociais de pescadores amazônicos. In Furtado, Leitão \& Mello (Org.). Povos das águas: realidade e perspectivas na Amazônia. (pp.231-242). Pará. Museu Paraense Emílio Goeldi.

Costa, P. (2012). Os impactos ambientais sobre a planície costeira bragantina: da construção da PA-458 a ocupação desordenada na praia de Ajuruteua. Paper presented at II Congresso Brasileiro de Gestão Ambiental. Instituto Brasileiro de Estudos Ambientais, Goiás, PT. Retrieved from Os impactos ambientais sobre a planície costeira bragantina: da construção da PA-458 a ocupação desordenada na praia de Ajuruteua - PDF Download grátis (docplayer.com.br)

Costa, J. (2014). As Novas Regras do Jogo para o Acesso aos Recursos Naturais na Reserva Extrativista Marinha de Tracuateua, no Pará. (Tese de Doutorado). Retrieved from http://www.ibama.gov.br/sophia/cnia/teses/josenewtonc ostatese.pdf

Cunha, M., \& Almeida, M. (2001). Populações Indígenas, Povos Tradicionais e Preservação na Amazônia. In Capobianco, J. (Org.). Biodiversidade na Amazônia brasileira: avaliação e ações prioritárias para a conservação, uso sustentável e repartição de 
benefícios. (pp. 184-193). São Paulo. Instituto Socioambiental e Estação Liberdade

Diani, M. (1992). The concept social movement. The Sociological Review. V. (40). Retrieved from The Concept of Social Movement - Mario Diani, 1992 (sagepub.com)

Diegues, A. (1996). O mito moderno da natureza intocada. São Paulo. HUCITEC-NUPAUB.

Diegues, A. (2004). A pesca construindo sociedades: leituras em antropologia marítima e pesqueira. São Paulo. HUCITEC-NUPAUB.

Fernandes, E., \& Souza, S. (2009). I Encontro Nacional das Reservas Extrativistas Costeiro-Marinhas:

Desenvolvimento com sustentabilidade. Relatório Final. Organização: Instituto Chico Mendes de Conservação da Biodiversidade e Ministério do Meio Ambiente.

Godelier, M. (1984). Território e propriedade em algumas sociedades pré-capitalistas. In Godelier, M. 0 ideal e o material: pensamento, economias, sociedades (pp. 1-27). Paris. Fayard. Retrieved from Microsoft Word - O ideal e o material Godelier cap 2 (usp.br)

Gonçalves C. (2001). Amazônia, Amazônias. São Paulo. Contexto.

ICMBio (2018). Atlas dos Manguezais do Brasil. Brasilia. Retrieved from https://acervo.socioambiental.org/sites/default/files/doc uments/17L00001.pdf

ICMBio (2020). Painel Dinâmico de Informações do ICMBio. Disponivel:

http://qvicmbio.gov.br/QvAJAXZfc/opendoc2.htm?document =painel_corporativo_6476.qvw\&host=Local\&anonymous=tru e

Lavalle, A., Carlos, E., \& Dowbor, M. Szwako, J. (2017). Movimentos sociais, institucionalização e domínios de agência. In Movimentos sociais e institucionalização: políticas sociais, raça e gênero no Brasil pós-transição. Rio de Janeiro: EdUERJ.

Little, P. (2004). Territórios sociais e povos tradicionais no Brasil: por uma antropologia da territorialidade. Anuário Antropológico/2002-2003. Rio de Janeiro. Tempo Brasileiro. Retrieved from Territorialidade social no Brasil contemporâneo (socioambiental.org)

Lopes, E. (2016). Estratégias e experiências de participação: um estudo com os usuários da Resex Marinha Caeté-Taperaçu em Bragança/Pará.
(Dissertação de mestrado). Retrieved from Microsoft Word - Erica Lopes- dissertação corrigida (ufpa.br)

Lopes, J., \& Heredia, B. (org.) (2014). Movimentos sociais e esfera pública: o mundo da participação. Rio de Janeiro. CBAE. Retrieved from Movimentos Sociais e Esfera Pública_MIOLO_CURVAS.indd (ipea.gov.br)

Melucci, A. (1980). The new social movements: a theoretical approach. Social Science Information. V. (19), pp. 199-226. Retrieved from The new social movements: A theoretical approach - Alberto Melucci, 1980 (sagepub.com)

Oliveira, M. (2015). A estrada para o "progresso": política, cultura e natureza em Bragança, Pará (19701996). (Dissertação de mestrado). Retrieved from RIUFPA

Oliveira, M. (2016). Movimento para as instituições: ambietalistas, partidos políticos e a liderança de Marina Silva. (Tese de doutorado). Retrieved from https://repositorio.unb.br/bitstream/10482/22095/1/2016 _Mar\%c3\%adliaSilvadeOliveira.pdf

Oliveira, M., \& Maneschy, M. (2014). Territórios e territorialidades no extrativismo de caranguejos em Pontinha de Bacuriteua, Bragança, Pará. Bol. Mus. Para. Emílio Goeldi. Cienc. Hum. V. (9), pp. 129-143. Retrieved from territorios(oliveira).indd (scielo.br)

Peres, A. (2011). Estudo antropológico de uma comunidade na abrangência da Reserva Extrativista Marinha Caeté-Taperaçu (Bragança-Pará-Brasil). (Unpublished doctoral thesis). Universidade Federal do Pará. Pará.

Reis da Silva, P. (2014). Saber fazer e poder fazer a construção social e política da Resex Caeté-Taperaçu. (Dissertação de mestrado). Retrieved from SABER FAZER E PODER FAZER A Construção Social e Política da RESEX Caeté-Taperaçu (Ana Patrícia Reis da Silva).pdf (ufpa.br)

Snow, D., Burke, R., Steven, K. Benford, R. (1989). Frame alignment processes, micromobilization, and movement participation. American Sociological Review. V. (51), pp.464-481. Retrieved from Frame Alignment Processes, Micromobilization, and Movement Participation on JSTOR

Sousa, V. (2019). A minha terra é o mar: a trajetória de um movimento socioambiental no litoral da Amazônia. (Trabalho de conclusão de curso). Retrieved from (1) (PDF) A MINHA TERRA É O MAR A TRAJETÓRIA DE 
UM MOVIMENTO SOCIOAMBIENTAL NO LITORAL DA AMAZÔNIA | victor sousa - Academia.edu

Sousa, V., \& Ribeiro, T. (2021, fevereiro). O maretório: a ressignificação de um conceito como categoria política por populações pesqueiras e extrativistas do litoral do Pará. Paper presented at III Seminário Internacional América Latina: democracia, natureza e epistemologias para pensar o amanhã. Universidade Federal do Pará, PT. Retrieved from ProgramacaoFinal-GT04.pdf (produtoracolaborativa.com.br)

Svampa, M. (2016). Extrativismo neodesenvolvimentista e movimentos sociais: um giro ecoterritorial rumo a novas alternativas? In Dilger; Lang; Filho (Org.). Descolonizar o imaginário: debate sobre pós-extrativismo e alternativas para 0 desenvolvimento. (pp. 141-171). São Paulo. Rosa Luxemburgo.

Tarrow, S. (1998). O poder em movimento: movimentos sociais e confronto político. Rio de Janeiro. Editora Vozes.
Tilly, C. (2010). Movimentos sociais como políticas. Revista de Ciência Política. V. (3), pp. 133-160. Retrieved from Mov. Sociais como política - Tilly.pdf (usp.br)

Viola, E. (1987). O movimento ecológico no Brasil (1974-1986): do ambientalismo à ecopolítica. Retrieved from O movimento ecológico no Brasil (1974-1986): do ambientalismo à ecopolítica (socioambiental.org)

Viola, E., \& Viera, P. (1992). Da preservação da natureza e do controle da poluição ao desenvolvimento sustentável: um desafio ideológico e organizacional ao movimento ambientalista no Brasil. Revista De Administração Pública. V. (4), p. 81-104. Retrieved from Da preservação da natureza e do controle da poluição ao desenvolvimento sustentável: um desafio ideológico e organizacional ao movimento ambientalista no Brasil | Revista de Administração Pública (fgv.br) 